\title{
Early gastric cancer: 46 cases treated in one surgical department
}

\author{
H M Sue-Ling, I Martin, J Griffith, D C Ward, P Quirke, M F Dixon, A T R Axon, \\ M J McMahon, D Johnston
}

\begin{abstract}
Forty six consecutive patients with early gastric cancer were treated between 1970 and 1990. The proportion of cases of early gastric cancer increased significantly $(p<0.01)$ from $1 \%$ of all cases in the first five year period to $15 \%$ in the last five year period, because of greater awareness of the condition and more widespread use of endoscopy. There were 33 men and 13 women, of median age 69 years (range 38-86). Most patients (91\%) presented with symptoms indistinguishable from those of peptic ulceration. The median duration of symptoms was four months (range 0.1-36 months). All 46 patients were treated surgically. Three patients (6.5\%) died after operation and a further 10 (22\%) suffered postoperative complications. None of the surviving patients has been lost to follow up and 25 have been followed up for a minimum period of five years. Five year survival by life table analysis was $\mathbf{9 8 \%}$. These findings suggest that in Britain in the 1990s, as in Japan, it may be possible to diagnose an increasing proportion of patients with gastric cancer at a relatively early pathological stage, when most patients can be cured by radical surgical resection with lymphadenectomy. (Gut 1992; 33: 1318-1322)
\end{abstract}

In Japan, a high proportion of patients with gastric cancer are diagnosed at the stage of early gastric cancer, when the disease has not yet penetrated the muscular layer of the gastric wall. About $90 \%$ of such patients are cured in Japan by radical surgery, in which gastric resection is accompanied by extensive lymphadenectomy. ${ }^{1}$

In Britain, until recently, only about $1 \%$ of all cases of gastric cancer were diagnosed at this early stage and only $5 \%$ of all cases of gastric cancer survived for five years. ${ }^{2}$ Hence, not surprisingly, a diagnosis of gastric cancer was regarded as virtually a sentence of death. Since about 1980, however, a few more encouraging reports of earlier diagnosis have appeared, ${ }^{3-5}$ raising the question of whether patients in Britain with early gastric cancer would fare as well after radical surgical treatment as their Japanese counterparts. In this paper, we report our own experience of 46 consecutive patients with early gastric cancer who were treated in the University Department of Surgery at Leeds General Infirmary.

Methods

PATIENTS

Between 1970 and 1990, 510 consecutive patients with gastric cancer were treated in the University Department of Surgery at Leeds General Infirmary. Forty six were found to have early gastric cancer, as defined by the Japanese Gastroenterological Endoscopic Society. ${ }^{6}$ There were 33 men and 13 women, of median age 69 (38-86) years (Fig 1). Forty two (91\%) presented with upper gastrointestinal tract symptoms (Table I), the most frequent of which was epigastric pain or 'dyspepsia'. The remaining four patients $(9 \%)$ were asymptomatic; two were discovered to have iron deficiency anaemia while in hospital for other conditions, one was found on routine endoscopy for a benign oesophageal stricture and the fourth at laparotomy for a ruptured abdominal aortic aneurysm. The diagnosis of gastric cancer was confirmed by endoscopy and biopsy alone in 30 cases (65\%), and by a combination of barium meal, endoscopy and biopsy in 16 cases (35\%). Nine patients (20\%) required repeated biopsies before the diagnosis of carcinoma was finally established.

\section{SURGICAL TREATMENT}

Of the 46 operations, $28(61 \%)$ were carried out by consultants and $18(39 \%)$ by lecturers/senior registrars. There were $16 \quad(35 \%)$ total gastrectomies, 26 (56\%) subtotal gastrectomies and four (9\%) oesophagogastrectomies. Since 1978, the standard surgical approach has C. sisted of wide gastric resection with radical (R2) lymphadenectomy, in which the second tier of lymph nodes (N2), beyond the perigastric nodes $(\mathrm{N} 1)$, is removed. In a few patients, a less radical procedure was still performed if such radical surgery was judged inappropriate on account of the patient's advanced age or serious associated disease. All total gastrectomy procedures were accompanied by Roux-en-Y reconstruction with a $40-50 \mathrm{~cm}$ Roux loop of jejunum, to keep bile and pancreatic juices out of the oesophagus and respiratory tract. Polya reconstruction was normally used after subtotal gastrectomy.

PATHOLOGY

Macroscopically, the early gastric cancer tumours

TABLE I Presenting symptoms of 42 patients with early gastric cancer ${ }^{\star}$

\begin{tabular}{ll}
\hline Symptoms & Frequency \\
\hline Epigastric pain or discomfort & $73 \%$ \\
Nausea and//or vomiting & $49 \%$ \\
Weight loss & $24 \%$ \\
Anorexia & $18 \%$ \\
Gastrointestinal bleeding & $11 \%$ \\
\hline
\end{tabular}

^ Four patients were asymptomatic (see text).
Gastroenter

A T R Axon

Correspondence to:

University Department of

Surgery, The General

Accepted for publication

24 February 1992 


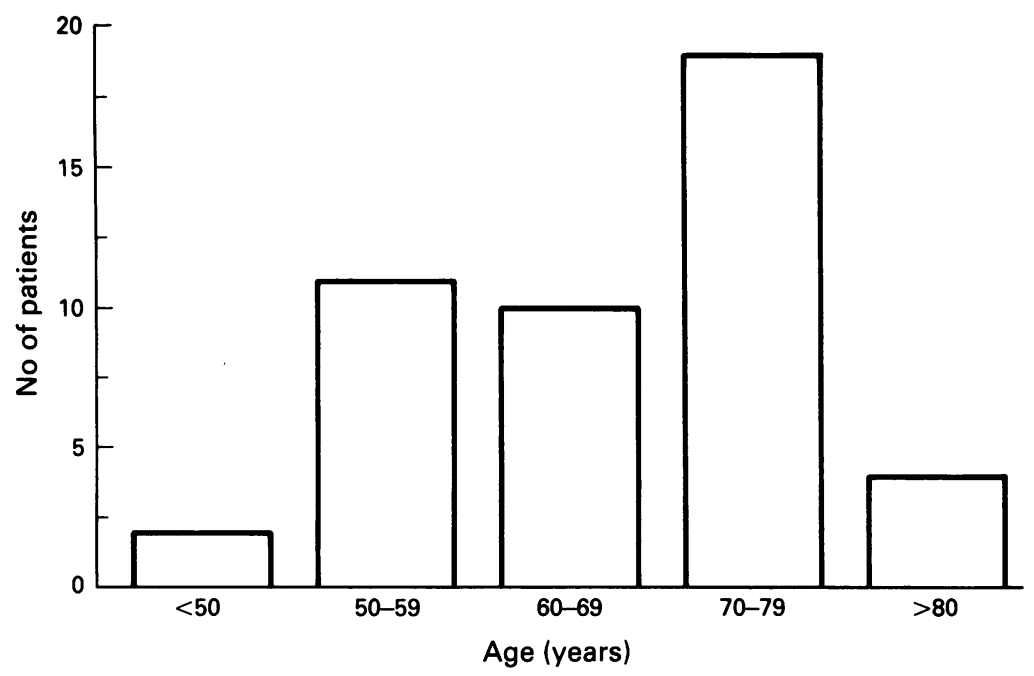

Figure 1: Age distribution of 46 patients with early gastric cancer.

were classified ${ }^{6}$ into three main types: protruded (I), superficial (II), and excavated (III). The superficial type II was further subdivided into three subtypes: IIa (raised), IIb (flat), IIc (depressed). Types IIc and III were the commonest tumours (61\%) found. Microscopically, 21 cases $(46 \%)$ were confined to the gastric mucosa and 25 (54\%) had penetrated to submucosa but had not breached the muscularis propria. There were five cases $(11 \%)$ with lymph node involvement (four N1, one N2), all from tumours which had penetrated the submucosa. Both proximal and distal resection margins were clear except in two cases (4\%), both of which occurred early in the series, before the use of intra-operative frozen section examination had become routine.

FOLLOW UP

Patients were reveiwed every three months for one year and six monthly thereafter at a special gastric follow up clinic, which was attended by a senior physician and surgeon. None of the 46 patients had been lost to follow up and $25(54 \%)$ have been followed up for a

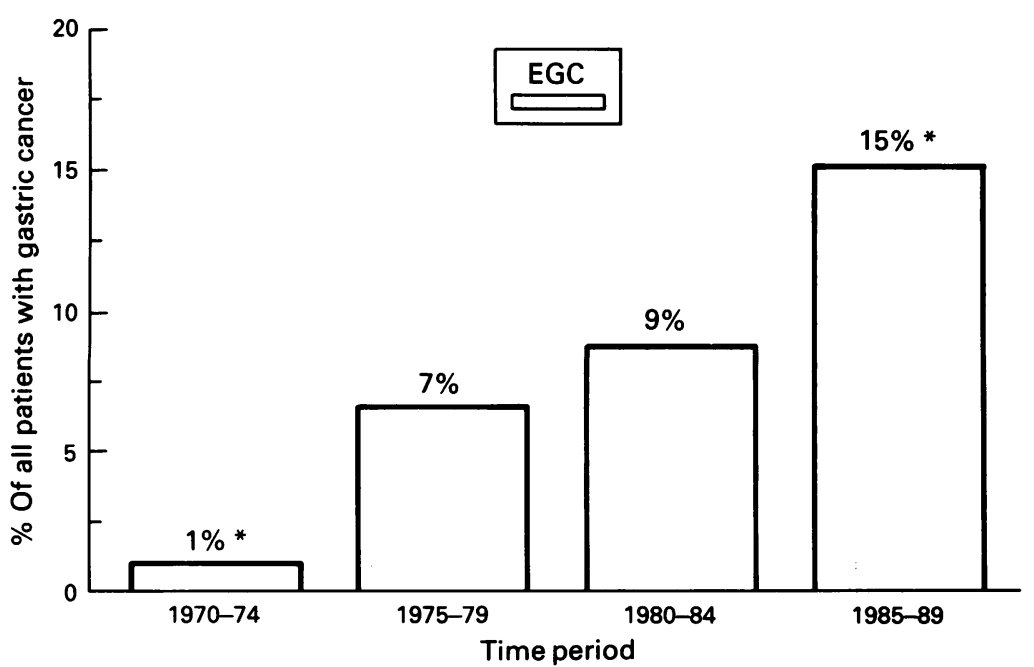

Figure 2: Proportion of cases of gastric cancer presenting as early gastric cancer (EGC) in each quinquennium $\left({ }^{\star} p<0.01\right)$. minimum period of five years. At each visit, the patient's weight, full blood count, symptoms and overall functional outcome by the Visick scoring system ${ }^{7}$ were recorded. If recurrence was suspected clinically, an endoscopic examination and ultrasound or computed tomographic (CT) scan were arranged. The cause of death was ascertained from our own and general practitioners' records and from the Yorkshire Regional Cancer Registry.

\section{STATISTICAL ANALYSIS}

Survival curves were constructed by life table analysis. ${ }^{8}$ The $\chi^{2}$ test was used to compare proportions of early gastric cancers to all cases of gastric cancer in each five year and 10 year period.

\section{Results}

DIAGNOSIS OF EARLY GASTRIC CANCER

The proportion of cases of early gastric cancer to all cases of gastric cancer in each five year period is shown in Figure 2. There was a significant $(p<0.01)$ increase in the proportion of cases of early gastric cancer, from $1 \%$ of all cases of gastric cancer in the first five year period to $15 \%$ in the last five year period, and from $5 \%$ in the 1970 s to $12 \%$ in the 1980 s. The increasing proportion of cases of early gastric cancer coincided with a four-fold increase in the number of upper gastrointestinal endoscopies performed (Fig 3).

\section{OPERATIVE MORTALITY}

Three patients (6.5\%) died after operation. A 78 year old woman died of heart failure six days after oesophagogastrectomy. Two men, aged 69 and 72 years, died as a result of anastomotic leakage, sepsis, and haemorrhage. A further 10 patients $(22 \%)$ sustained postoperative complications (Table II).

\section{SURVIVAL}

Cumulative survival, calculated by life table analysis, was $98 \%$ at five years. Of the 25 patients with a minimum (potential) follow up of five years, and after exclusion of deaths unrelated to gastric cancer, $95 \%$ (18 of 19 patients) actually survived for more than five years (six patients died of causes other than gastric cancer). The only patient who died of recurrent disease within five years of operation was an 80 year old man who had undergone a non-radical gastrectomy, on account of his advanced age and frailty. The remaining 18 patients have been followed up for less than five years: none has developed recurrent carcinoma, two have died of causes unrelated to gastric cancer and 16 are alive and well.

There were two patients with resection margin involvement early in the series, who were thus at high risk of local recurrence. One died of myocardial infarction three years after operation, with no evidence of recurrent disease. The other patient lived for six and a half years after operation before succumbing to recurrent 
Figure 3: Number of endoscopic examinations performed in the Gastroenterology Unit at Leeds General Infirmary from 1976 to 1990.

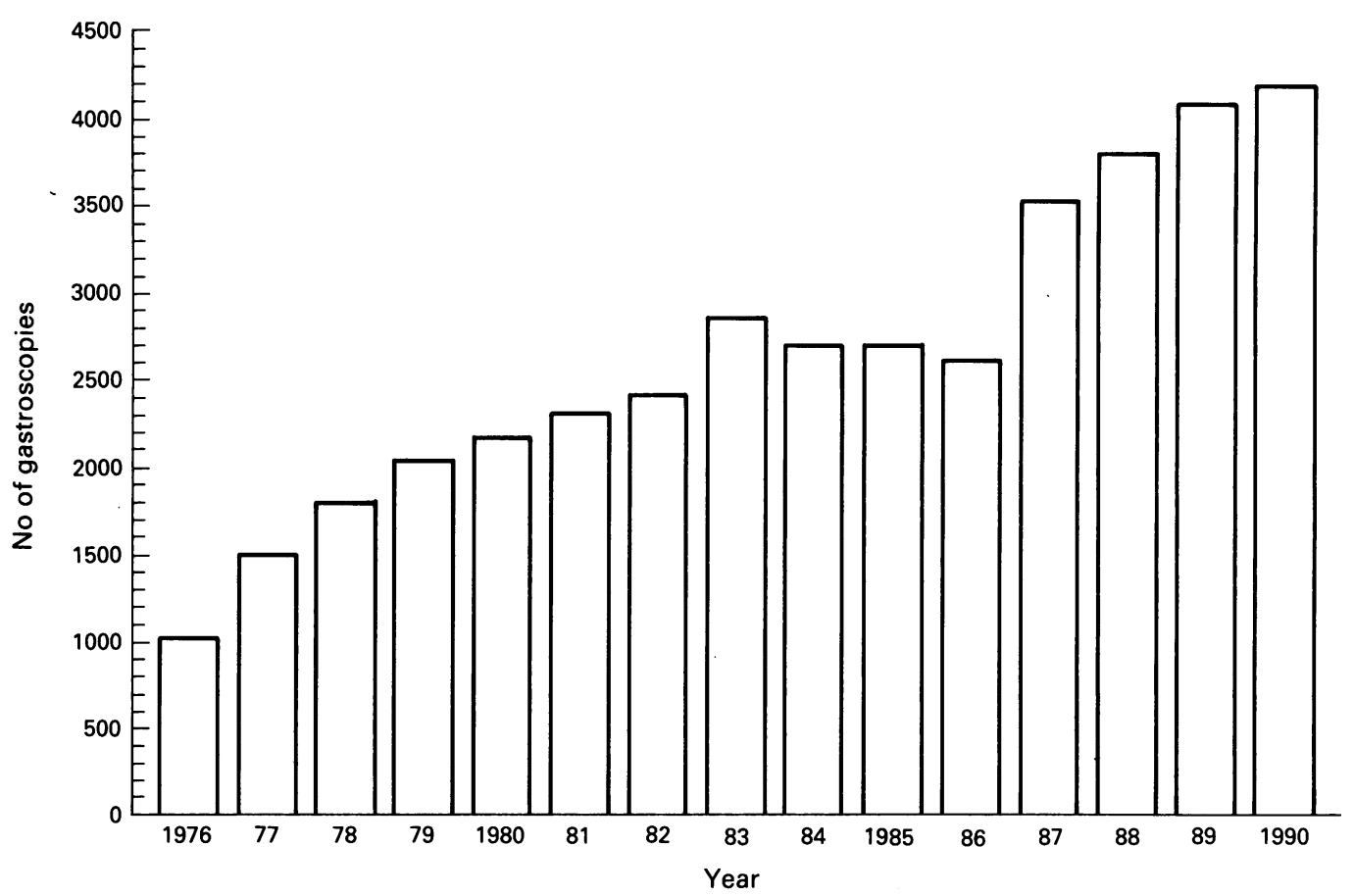

carcinoma. Thus, no patient who survived operation, and who had undergone radical, potentially curative resection, died of recurrent disease.

\section{QUALITY OF LIFE}

Patients' quality of life after radical total or subtotal gastrectomy was found to be surprisingly good. Eighty three per cent of patients achieved a good to excellent functional result (Visick grades I and II), while only $17 \%$ had a moderate or poor result (Visick grades III or IV). When questioned about the size of meal that they could eat, $43 \%$ of patients claimed to be able to eat normal meals. Mean weight at least six months after operation was 58.7 (13.4) $\mathrm{kg}$ (mean (SD)) compared with a preoperative (recall) best weight of $63.4(13.4) \mathrm{kg}$ (mean (SD)). Haemoglobin concentration one year after operation was $12 \cdot 7$ $(1 \cdot 0) \mathrm{g} / \mathrm{dl}$ (mean (SD)). Most patients (77\%) were able to maintain a normal level of haemoglobin $(12-16 \mathrm{~g} / \mathrm{dl})$.

\section{Discussion}

Although the incidence of carcinoma of the stomach is decreasing, gastric cancer still accounted for 100000 deaths in England and Wales between 1980 and 1989, ${ }^{9}$ ranking in frequency only behind carcinoma of bronchus, colon and rectum, and breast as a cause of death from cancer. The five year survival of patients with cancer of stomach in the Birmingham region between 1957 and 1981 was reported to be $5 \%,{ }^{2}$ though these figures may not be applicable to the 1980s. Thus, a diagnosis of gastric cancer has come to be regarded as virtually a sentence of death. Even the spectacularly better results reported after surgical treatment of gastric cancer in Japan, with five year survival in excess of $50 \%,{ }^{10-12}$ did little to relieve the gloom, as it was felt that the Japanese must be dealing with a different disease, less aggressive than gastric cancer in the West.

As far as we are aware, the present series represents the largest series of patients with early gastric cancer reported from a single centre in Britain, and our results compare favourably with other reports of early gastric cancer (Table III) from Japan, ${ }^{1314}$ Spain, ${ }^{15}$ the United States ${ }^{16}$ and Britain. ${ }^{17} 18$ We believe that these findings provide grounds for optimism, because we have shown that the proportion of cases of early gastric cancer (to all cases of gastric cancer) has increased significantly with more widespread use of endoscopy, from $1 \%$ in the early 1970 s to as high as $15 \%$ in the late 1980 s. Furthermore, all patients who survived radical surgical resection survived

TABLE II Postoperative complications in 46 patients with early gastric cancer

\begin{tabular}{lc}
\hline Complication & Frequency \\
\hline Chest infection & $4(9 \%)$ \\
Wound infection & $2(4 \%)$ \\
Deep venous thrombosis & $1(2 \%)$ \\
Myocardial infarction & $1(2 \%)$ \\
Haemorrhage & $1(2 \%)$ \\
Perforated gall bladder & $1(2 \%)$ \\
Total & $10(22 \%)$ \\
\hline
\end{tabular}

$\star$ Patients required reoperation.

TABLE III Results of surgical treatment of early gastric cancer

\begin{tabular}{llll}
\hline $\begin{array}{l}\text { Author and } \\
\text { year }\end{array}$ & Country & $\begin{array}{l}\text { Patients } \\
(\boldsymbol{n})\end{array}$ & $\begin{array}{l}\text { Five year } \\
\text { survival }^{\star}\end{array}$ \\
\hline Itoh (1989) & Japan & 109 & 96 \\
Inoue (1991) & Japan & 247 & 94 \\
Oleagoitia (1986) & Spain & 142 & 93 \\
Lawrence (1991)‡ & USA & 60 & 76 \\
De Dombal (1990)† & UK & 132 & 90 \\
Houghton $(1985)$ & UK & 35 & 925 \\
\hline
\end{tabular}

^Corrected 5 year survival (Kaplan Meier); † collected series from 41 centres in the UK; $¥$ data relate to period $1960-1988$, hence series in USA may be better now than the $76 \%$ five year survival quoted; \age adjusted five year survival. 
for five years. The only patient who died of recurrence within five years of operation underwent a 'peptic ulcer' type of operation, without lymph node dissection, because of his advanced age and frailty. As in the large Japanese series, ${ }^{13}$ more than $10 \%$ of our patients (five of 46 ) had involved lymph nodes: all of these patients survived for five years after radical, R2, lymphadenectomy. We know from Japanese experience, however, that five year survival in such patients would be significantly poorer than in cases with uninvolved lymph nodes, if larger numbers of patients were available for analysis. ${ }^{1+}$

The operative mortality of $6.5 \%$ (three of 46 patients) in this series is higher than the $1-3 \%$ reported after comparable surgery in Japan. ${ }^{1619}$ The difference may be attributable to several factors: the average age of our patients ( 69 years) is about 12 years older than that of patients with early gastric cancer in Japan' and our patients are likely to have been more obese and to have had more associated disease, notably ischaemic heart disease, than the Japanese patients. ${ }^{10}$ Hence, they are at greater operative risk. Again, operative mortality is likely to be higher in a surgical department where 'only' 30-50 cases a year undergo radical gastric resection than in a Japanese centre where many hundreds of patients undergo such resections each year. It may be relevant that the most experienced surgeon in our group had an operative mortality rate of $0 \%$. Finally, the $95 \%$ confidence limits of the $6 \%$ operative mortality are from $1.5 \%$ to $18 \%$, and so the observation of a 'higher' operative mortality than in Japan has little statistical validity.

It is debatable whether or not all patients with early gastric cancer should undergo radical surgical resection with extensive (R2) lymphadenectomy. It could be argued that any slight gain achieved by radical (R2) resection may be negated by an increase in operative mortality and morbidity. Lymphatic metastases in cases of early gastric cancer are largely confined to the perigastric lymph nodes less than $3 \mathrm{~cm}$ (N1) from the tumour, and only occasionally involve lymph nodes more than $3 \mathrm{~cm}(\mathrm{~N} 2)$ from the tumour. ${ }^{13}$ Again, the incidence of lymphatic metastases is directly related to the depth of invasion of the primary tumour, and ranges from $4 \%$ for tumours confined to the mucosa to $20 \%$ for tumours extending to the submucosa. ${ }^{132}$ In this study, 25 cases of early gastric cancer (54\%) had penetrated to the submucosa, and all five cases with nodal metastases were associated with tumours which had penetrated to the submucosa. Thus, it would seem logical to carry out a more conservative (R1) resection with complete excision of perigastric (N1) nodes in cases of early gastric cancer where the tumour was confined to the mucosa, reserving the more radical (R2) resection for cases where the tumour had penetrated to the submucosa.

There are a number of reasons, however, why such a policy is not practical at present. First, preoperative assessment of the depth of invasion of early gastric cancer would require the use of endoscopic endoluminal ultrasound, which is not yet available in many British centres. Even if it were available, accurate distinction between mucosal and submucosal tumours is not always achieved, even by experts. ${ }^{2122}$ This applies particularly to tumours of the depressed or excavated types (IIc and III) with ulceration which represented $61 \%$ of tumours in this series, because of the presence of fibrosis in the submucosa and underlying muscularis propria. The surgeon therefore does not know the exact TNM (tumour, node, metastasis) stage of the tumour at operation and a diagnosis of early gastric cancer is usually made in retrospect. Secondly, data from Japan ${ }^{2324}$ have consistently supported the view that the ' $R$ ' number $(0-3)$ of resection should exceed the ' $N$ ' number (0-3) of nodal metastases if recurrence is to be minimised and 'absolute' curative resection is to be achieved. The standard operation in Japan is an R2 resection, in which an extra 'tier' of lymph nodes (N2) is removed in addition to those close to the stomach (N1 nodes), which are normally removed as part of a wide gastric resection (known as $\mathrm{R} 1$ resection). As up to $20 \%$ of patients with early gastric cancer may have metastases to N1 lympth nodes, it follows that $R 2$ resection should be the treatment of choice. Finally, there is little evidence that more radical (R2) resection leads to increased operative mortality or morbidity. ${ }^{10}$

Thus, until the techniques of endoscopic endoluminal ultrasound become more refined and more widely available, we believe that most patients who appear at operation to have an 'early' gastric cancer should undergo radical (R2) resection as Japanese authors continue to advocate. ${ }^{19}$ While it would seem reasonable to modify the extent of resection in a few high risk, obese, or elderly patients, the dangers of doing so are illustrated in this series by the death from recurrent cancer of an old man who had undergone a limited gastric resection on account of his age and frailty.

The excellent results that were reported recently after surgical resection for EGC in Britain $^{17}$ contrast starkly with the poor results reported after radical, potentially curative surgery for more 'advanced' types of gastric cancer, in which the tumour has penetrated the muscular wall of the stomach with frequent involvement of lymph nodes. These 'advanced' tumours account for most cases of operable gastric cancer in the Western world. Five year survival after operation in such patients in Britain ranges from only $16 \%$ to $38 \%{ }^{25-31}$ Hence, the key to improving survival for patients with gastric cancer in Britain is to achieve earlier diagnosis. We found, as others have reported previously, that the symptoms of EGC were very similar to the symptoms of benign conditions such as peptic oesophagitis, gastritis and peptic ulcer (Table I). Thus, as Gear, ${ }^{3}$ Hallissey, ${ }^{4}$ Kerrigan ${ }^{5}$ and others have pointed out, the most promising way in which the lives of some of the 10000 people who die from gastric cancer each year in the United Kingdom could be saved is to suspect any patient over the age of 45 years who presents with dyspepsia of having gastric cancer, and to confirm or refute that suspicion by means of prompt endoscopy, with biopsy of any suspicious lesion. Patients with dyspepsia in this age group should not be treated with antacids or potent anti-ulcer drugs before a diagnosis has 
been established by endoscopic examination, as such treatment may mask the symptoms of gastric cancer and lead to a delay in diagnosis. Only one of the 46 patients with early gastric cancer in this series was less than 40 years of age (38 years), and he underwent operation because he belonged to a 'gastric cancer family' and was known to have gastric dysplasia on biopsy, although he was not known before operation to have carcinoma. The next youngest patient was 49 years of age, but 13 of the 46 patients were under 60 years of age. Hence, the most efficient use of open access endoscopy would be to concentrate diagnostic efforts on patients with pain, dyspepsia or anaemia who are more than 45 years of age, or who belong to one of the high risk groups, such as those who have undergone partial gastrectomy, or truncal vagotomy and gastroenterostomy, or who have pernicious anaemia.

The quality of life of most of the survivors of radical total or subtotal gastrectomy in this series was unexpectedly good. In the past, after resection of the stomach and of the pyloric and cardiac sphincters, the oesophagus was anastomosed to a loop of jejunum, which resulted in copious reflux of intestinal content into the oesophagus and even the bronchial tree especially at night: hence, in many cases, the quality of life was poor. Today, the almost universal use of a Roux-en-Y jejunal segment after total gastrectomy has overcome this problem, and in consequence many patients enjoy a good quality of life, although the majority have to restrict the size of meals. Surprisingly, $43 \%$ of our patients claimed at follow up that they were able to eat normal meals, and weight loss compared with their best recall weight before operation was on average only $5 \mathrm{~kg}$. Only $17 \%$ of patients had a moderate or poor-(Visick grades III or IV) quality of life after subtotal or total gastrectomy. At the gastric follow up clinic, each patient receives regular advice about diet, and many also receive injections of vitamin $B_{12}$ every three months, and supplements of iron, calcium and vitamins as required. Thus it is likely that the regular follow up itself, with frequent checks of haematological status and the opportunity to discuss any problems and anxieties, may contribute to their relatively good state of health.

In conclusion, the outlook for patients with gastric cancer in Britain seems, at last, to be changing. The essential factor is that general practitioners and hospital doctors alike should be alert to the possible presence of gastric cancer in any patient over the age of 45 years who complains of dyspepsia or is anaemic, and that urgent investigation is the form of endoscopy and biopsy should be instituted. The surgeon's task is to perform, safely, an appropriately radical resection: resection margins should be proved to be free from tumour by means of frozen section examination and radical, (R2) lymphadenectomy should probably be performed in most patients in order to encompass involved lymph nodes, which are present in up to
$20 \%$ of patients with early gastric cancer. Our finding of $98 \% 5$ year survival by life table analysis among the 43 patients who survived radical surgery suggests that all, or nearly all, of the patients who are diagnosed as having early gastric cancer in Britain can be cured.

1 Itoh $\mathrm{H}$, Oohata $\mathrm{Y}$, Nakamura $\mathrm{K}$, Nagata T, Mibu R, Nakayama F. Complete ten-year postgastrectomy followup of early gastric cancer. Am F Surg 1989; 158: 14-6.

2 Allum WH, Powell DJ, McConkey CC, Fielding JWL. Gastric cancer: a 25 year review. Br f Surg 1989; 76: 535-40.

3 Gear MWL, Ormiston MC, Barnes RJ, Rocyn-Jones J, Voss GC. Endoscopic studies of dyspepsia in the community: an "open access" service. BMF 1980; 280: 1135.

4 Hallissey MT, Allum WH, Jewkes AJ, Ellis DJ, Fielding JWL. Early detection of gastric cancer. $B M F$ 1990; 301: 513-5.

5 Kerrigan DD, Brown SR, Hutchinson GH. Open-access gastroscopy: Too much to swallow? BMF 1990; 300: 374-6. 6 Murakami T. Early cancer of the stomach. World $\mathcal{F}$ Surg 1979; 3: 685-92.

7 Visick AH. A study of the failures after gastrectomy. Ann $R$ Coll Surg Engl 1948; 3: 266-84.

8 Kaplan EL, Meier P. Non-parametric estimation from incomplete observations. $\mathcal{F}$ Am Stat Assoc 1958; 53: 457-81.

9 Office of Population Censuses and Surveys. Mortality statistics by cause. London: HMSO, 1989.

10 Maruyama K, Okabayashi K, Kinoshita T. Progress in gastric cancer surgery in Japan and its limits of radicality. World $\mathcal{f}$ Surg 1987; 11: 418-25.

11 Mishima $Y$, Hirayama $R$. The role of lymph node surgery in gastric cancer. World f Surg 1987; 11: 406-11.

12 Noguchi Y, Imada T, Matsumoto A, Coit D, Brennan M. Radical surgery for gastric cancer. A review of the Japanese experience. Cancer 1989; 64: 2053-62.

13 Okamura T, Tsujitani S, Korenaga D, Haraguchi M, Baba H, Hiramoto $\mathrm{Y}$, et al. Lymphadenectomy for cure in patients with early gastric cancer and lymph node metastasis. $A m \mathcal{F}$ with early gastric cance

14 Inoue K, Tobe T, Kan N, Nio Y, Sakai M, Takeuchi E, et al. Problems in the definition and treatment of early gastric cancer. BrF Surg 1991; 78: 818-21.

15 Oleagoitia JM, Eschevarria A, Santidrian JI, Ulacia MA, Hernandez-Calvo J. Early gastric cancer. Brf S Surg 1986; 73: 804-6.

16 Lawrence $M$, Shiu MH. Early gastric cancer. Twenty-eight year experience. Ann Surg 1991; 213: 327-34.

17 DeDombal FT, Price AB, Thompson H, Williams GT, Morgan AG, Softley A, et al. The British Society of Gastroenterology early gastric cancer dysplasia survey: an interim report. Gut 1990; 31: 115-20.

18 Houghton PW, McC Mortensen NJ, Allan A, Williamson RCN, Davies JD. Early gastric cancer: the case for long term RCN, Davies JD. Early gastric cancer:
surveillance. $B M F$ 1985; 291: 305-8.

19 Hioki K, Nakane Y, Yamamoto M. Surgical strategy for early gastric cancer. Brf Surg 1990; 77: 1330-4.

20 Fukutomi H, Sakita T. Analysis of early gastric cancer cases collected from major hospitals and institutes in Japan. $\mathfrak{f p n}^{\mathcal{F}}$ Clin Oncol 1984; 14: 169-79.

21 Tio T, Schouwink M, Cikot R, Tytgat G. Pre-operative TNM classification of gastric carcinoma by endosonography in comparison with the pathological staging system: prospective study of 72 cases. Hepatogastroenterol 1989; 36: $51-6$.

22 Yasuda K, Kiyota K, Nakajima M, Kawai K. Fundamentals of endoscopic laser therapy (ELT) for GI tumours - new aspects with endoscopic ultrasonography (EUS). Endoscopy 1987; 19: 2-6.

23 Nakajima T, Nishi $M$. Surgery and adjuvant chemotherapy for gastric cancer. Hepatogastroenterology 1989; 36: 79-85.

24 Kodama Y, Sugimachi K, Soejima K, Matsuska T, Inokuchi $\mathrm{K}$. Evaluation of extensive lymph node dissection for carcinoma of the stomach. World $\mathcal{F}$ Surg 1981; 5: 241-8.

25 Hawley PR, Westerholm P, Morson BC. Pathology and prognosis of carcinoma of the stomach. Brf Surg 1970; 57: 877-83.

26 Cassell P, Robinson JO. Cancer of the stomach: a review of 854 patients. Brf Surg 1976; 63: 603-7.

27 Desmond AM Radical surgery in treatment of carcinoma of stomach. Proc R Soc Med 1976; 69: 867-9.

28 Costello CB, Taylor TV, Torrance B. Personal experience in the surgical management of carcinoma of the stomach. $B r \mathcal{F}$ Surg 1977; 64: 47-51.

29 Lygidakis NJ. Total gastrectomy for gastric carcinoma: a retrospective study of different procedures and assessment of a new technique of gastric reconstruction. Br $\mathcal{F}$ Surg 1981 68: 649-55

30 Cunningham D, Hole D, Taggart DJ, Soukop M, Carter DC, McArdle CS. Evaluation of the prognostic factors in gastric cancer: the effect of chemotherapy on survival. Br $尹$ Surg 1987; 74: 715-20.

31 Akoh JA, Sedgwick DM, Macintyre IMC. Improving results in the treatment of gastric cancer; an 11-year audit. Brf Surg 1991; 78: 349-51. 